\title{
Formation of lithiated gold and its use for the preparation of reference electrodes - an EQCM study
}

\author{
Christopher Behling ${ }^{1,2} \cdot$ Karl J. J. Mayrhofer $^{1,2} \cdot$ Balázs B. Berkes $^{1} \mathbb{C}$
}

Received: 29 June 2021 / Revised: 28 September 2021 / Accepted: 29 September 2021 / Published online: 11 October 2021

(c) The Author(s) 2021, corrected publication 2022

\begin{abstract}
Lithiated gold wires can be used to build reference electrodes with outstanding potential stabilities over several days and even over the course of one year. These electrodes are well suited for investigations in the context of lithium-ion batteries (LIBs). In this work, a detailed procedure for the preparation of such electrodes with tailored mechanical properties, which can be fitted gastight into electrochemical cells using commercially available fittings, is given. The electrochemical lithiation process is studied using the electrochemical quartz crystal microbalance (EQCM) technique, and the differences in lithiation of wire type and thin film type gold electrodes are discussed. All experiments were carried out with two different electrolytes, namely, a $\mathrm{LiPF}_{6}$ and a lithium bis(trifluoromethane sulfonyl) imide (LiTFSI)-based electrolyte, and we conclude that for a higher lithiation rate and long-term stability, the use of LiTFSI-based electrolyte in the preparation phase is beneficial. The EQCM data provides a better insight in the analysis of film formation processes, like the buildup of the solid electrolyte interphase (SEI) during the lithiation, the rate of deposition of metallic lithium, or additional information on the kinetics of Li-Au alloy formation.
\end{abstract}

Keywords Gold-lithium alloy $\cdot \mathrm{SEI}$ formation $\cdot \mathrm{LiPF}_{6} \cdot \mathrm{LiTFSI} \cdot$ Lithiation $\cdot$ Reference electrodes

\section{Introduction}

Lithium-ion batteries (LIBs) represent the most important achievement among modern electrochemical energy storage devices that fundamentally changed our society through portable electronics and electric vehicles. The ever-growing demand for higher energy density LIBs requires new ways and technologies to meet the needs for their future development. An important step in battery performance improvement is gaining deeper understanding of underlying electrochemical processes, accompanied by thorough electrochemical testing and characterization, as well as the

This paper is dedicated to Prof. Inzelt on the occasion of his 75th birthday.

Balázs B. Berkes

b.berkes@fz-juelich.de

1 Helmholtz Institute Erlangen-Nürnberg for Renewable Energy (IEK-11), Forschungszentrum Jülich, Cauerstr. 1, 91058 Erlangen, Germany

2 Department of Chemical and Biological Engineering, Fried rich-Alexander-Universität Erlangen-Nürnberg, Cauerstr. 1, 91058 Erlangen, Germany development of sophisticated measurement methods. Studies in full battery cells are in that sense sometimes limiting, as they always contain overlapping information of both, anodic and cathodic, processes. In contrast, three electrode electrochemical cells, which employ a reference electrode with well-defined and stable electrode potential, can separate the characterization of cathode and anode active materials and thus provide more straightforward insights into half reactions. However, the choice of the right reference electrodes in nonaqueous systems is not obvious. Due to the large number of applied solvents, solvent mixtures, and electrolyte salts, it is hardly possible to find a commercial reference electrode fitting all the experimental requirements. Aqueous electrochemistry in this respect is in many cases simpler, and companies offer many possibilities for commercially available, diverse reference electrodes. An excellent compilation of both aqueous and nonaqueous reference electrodes can be found in the Handbook of Reference Electrodes edited by G. Inzelt et al. [1].

In case of LIB research, the $\mathrm{Li} / \mathrm{Li}^{+}$system, a piece of lithium wire or foil in contact with a lithium ion containing electrolyte as half-cell, is probably the most widely used reference electrode. But in many cases, this half-cell serves 
as both the counter and the reference electrode at the same time. This might be problematic even with well-established cell designs, such as coin type cells, Swagelok T cells, or pouch/coffee bag cells due to the known issue with lithium dendrite formation, especially in consecutive charge/discharge experiments. Another problem of using Li as counter and reference electrode simultaneously has been demonstrated by LaMantia et al. [2]. At high current densities, the behavior of Li becomes stochastic; i.e., the potential difference between lithium and the working electrode (WE) changes due to the polarizability of lithium. To overcome these problems, lithium might be used as the reference electrode by inserting it into the separator or in between two separator sheets [3-5]. This insertion of lithium metal can, however, be problematic due to the mechanical properties of the metal. It is soft, malleable, and easy to deform. Therefore, it is usually attached to a copper, nickel, or stainless-steel wire. The size of the so obtained reference electrodes, however, is relatively big and can disturb the electric field between the cathode and anode and falsify sensitive measurements, like impedance spectroscopy, via non-ideal positioning relative to the other electrodes [6, 7].

An alternative solution to lithium is the use of cathode materials, like $\mathrm{Li}_{4} \mathrm{Ti}_{5} \mathrm{O}_{12}$ or $\mathrm{LiFePO}_{4}[2,8]$ or lithium metal alloys $[9,10]$ for the preparation of reference electrodes for nonaqueous electrolytes. And the use of so-called point type reference electrodes helps to significantly improve the quality and reproducibility of sensitive measurements. These reference electrodes are composed of a thin wire with an electronic insulator on its surface, being exposed to the electrolyte only at its end. Intensive studies showed that metal wires forming an alloy with lithium show superior stability compared to in situ deposited thin lithium films [11-13]. However, through a continuous growth of the solid electrolyte interphase (SEI), such thin films can be delithiated, limiting the lifetime of the reference electrode.

Recently, gold has attracted the attention of researchers in the field of LIBs as a possible reference electrode after lithiation [13, 14]. Both cited works describe the use of gold for the preparation of micrometer sized wire reference electrodes. In earlier studies, as a noble metal gold was rather used as a model system for fundamental investigations, like the reduction or oxidation reactions of battery electrolytes [15], however, its electrochemical lithiation has also been reported as early as 1971 [16].

For the real-time monitoring of dissolution processes in nonaqueous electrolytes, we have recently developed an electrochemical flow cell [17-19]. One particular challenge for battery research with this approach was the reference electrode, which also herein needs to feature reproducible and stable electrode potentials, a well-defined shape, and mechanical stability so that a tight installation into close vicinity of the WE is possible. We decided for a gold wire reference electrode mounted into a PEEK capillary as a housing for the wire. The lithiation process of a gold wire is described in [13], although in this case not a whole wire was lithiated, but only the tip of an insulated gold wire which was exposed to the electrolyte (the cross sectional area). Most of the remaining gold lithiation experiments reported utilize thin films, sputtered either onto a $\mathrm{Cu}$ substrate $[20,21]$ or onto a $\mathrm{W}$ wire [14].

During the first gold wire lithiations with a $\mathrm{LiPF}_{6}$ containing electrolyte, we experienced many peculiarities with huge discrepancies between the reported current-time curves and our own results. Switching from $\mathrm{LiPF}_{6}$ to lithium bis(trifluoromethane sulfonyl) imide (LiTFSI) just partially solved the problem, so we decided to investigate the phenomena deeper, utilizing the electrochemical quartz crystal microbalance (EQCM) technique. It has the advantage that it employs thin Au films deposited onto quartz, thereby conforming to previous studies, while also being a very sensitive technique for surface mass changes. Due to big differences in the construction and composition of the SEI in the two applied electrolytes, this latter aspect seemed to be especially beneficial.

The EQCM is mainly a surface mass sensitive method, widely used in investigations including metal and alloy deposition, underpotential deposition (UPD) or electroplating just to mention a few. A book chapter written by G. Inzelt gives a good overview of the method through selected applications by the author [22]. The mass changes occurring during deposition processes together with the simultaneously measured electrochemical data can be very helpful for the elucidation of reaction mechanisms via identification of the species accumulated on the surface. The method has also been used for investigations of LIB systems. In the 1990s, it was used to study the behavior of battery electrolyte solutions on Au electrodes [23], for the study of the deposition and stability of SEI forming Li compounds in the UPD region of lithium [24] or to monitor the mass change of electrodeposited $\mathrm{Li}$ on $\mathrm{Ni}$-coated crystals [25]. Nowadays, it is mainly used to investigate intercalation processes at both the cathode and anode or formation of SEI on graphite, usually together with dissipation monitoring taking into account the porous structure of the layers [26, 27]. However, to the best of our knowledge, it has so far never been used to monitor alloy formation between $\mathrm{Li}$ and Au during long-term galvanostatic $\mathrm{Li}$ deposition that is of interest in relation with the preparation of our PEEK embedded lithiated gold wire reference electrodes (AuLi-Ref).

As it has been very well described in the preface of [1]: "In order to produce reliable experimental data, reference electrodes have to fulfill many, partly contradictory conditions, which practically never can be met to full satisfaction. For the choice and application of a particular reference electrode it is of utmost importance to know its properties as detailed as possible." Therefore, we decided to dedicate a detailed study to the preparation of macroscopic sized $\mathrm{Au} /$ 
Li reference electrodes that can be used in a huge variety of electrochemical cells to study nonaqueous systems, especially LIBs.

\section{Experimental}

\section{Materials}

The battery electrolytes $\operatorname{LiPF}_{6}\left(1 \mathrm{~mol} \cdot \mathrm{L}^{-1}\right.$ in EC:EMC, 3:7 by wt.) and LiTFSI ( $1 \mathrm{~mol} \cdot \mathrm{L}^{-1}$ in EC:EMC, $3: 7$ by wt.) used for the experiments were bought from E-Lyte Innovations $\mathrm{GmbH}$ (Münster, Germany). The silver salt $\mathrm{AgClO}_{4}$ (anhydrous) which was used for the calibration of the EQCM was obtained from Alfa Aesar (by Thermo Fisher GmbH, Kandel, Germany). Silver (99.9\%; 0.25 mm outside diameter, OD), gold (99.9\%; $0.25 \mathrm{~mm}$ OD), and platinum (99.99\%; $0.25 \mathrm{~mm}$ OD) wires as well as lithium foil $(99.8 \%$; $0.5 \mathrm{~mm})$ were from MaTecK (MaTecK Material-Technolgie \& Kristalle GmbH, Jülich, Germany). The glassy carbon rods (SIGRADUR $® \mathrm{G} ; 1 \mathrm{~mm}$ OD) used for potential stability measurements of the AuLi-Ref were purchased from HTW Hochtemperatur-Werkstoffe GmbH (Thierhaupten, Germany). All crystals for the EQCM, namely, Au-Ti (5 MHz, $100 \mathrm{~nm} \mathrm{Au}$ on thin Ti adhesion layer) and $\mathrm{Au}-\mathrm{Cr}(5 \mathrm{MHz}$, $100 \mathrm{~nm} \mathrm{Au}$ on thin $\mathrm{Cr}$ adhesion layer), were obtained from MicroVacuum Ltd. (Budapest, Hungary). The PEEK electrode bodies (LF-1.6; Leak-Free Reference Electrode Junction, $1.6 \mathrm{~mm}$ OD, $1.0 \mathrm{~mm}$ ID), which were used for the assembly of the reference electrodes, were ordered from Innovative Instruments, Inc. (Tampa, FL, USA).

\section{Instruments}

All experiments were performed inside an Ar filled glovebox (M. BRAUN Inertgas-Systeme GmbH, Garching, Germany) with water and oxygen levels $<1 \mathrm{ppm}$. Electrochemical measurements were conducted with either an SP-300 or a VSP-300 potentiostat by Biologic Sciences Instruments (Seyssinet-Pariset, France). The EQCM device (eQCM-I Mini) was obtained from MicroVacuum Ltd. (Budapest, Hungary).

\section{Cells}

EQCM measurements were carried out in a temperature controlled cell of the type "QSHE-open" at $25{ }^{\circ} \mathrm{C}$ (MicroVacuum Ltd.) using a modified lid. Lithiation experiments of gold wires were performed in homemade 2-electrode cells of either polypropylene or glass. These cells were built by modification of chromatography sample vials of varying volumes depending on the desired immersed length of the wires into the electrolyte. In all cells, a piece of lithium foil fixed to a copper wire served as the counter electrode (CE), while the gold wires or EQCM-crystals were used as the WEs.

\section{Calibration}

The calibration of the EQCM was carried out using a spiral $\mathrm{Ag}$ wire as the counter and reference electrode and $0.1 \mathrm{~mol} \cdot \mathrm{L}^{-1} \mathrm{AgClO}_{4}$ added into the different electrolytes. Silver was chosen as the calibration system because its redox potential lies within the stability windows of the electrolytes, while also not being able to form alloys with the used Au crystals. During the calibration, constant current densities of 200,20 , and $2 \mu \mathrm{A} \cdot \mathrm{cm}^{-2}$ were applied consecutively between the Au quartz and the $\mathrm{Ag}$ wire for 2 min each while monitoring the frequency change. First negative currents were applied to deposit silver, then positive currents were used to redissolve the deposited $\mathrm{Ag}$ atoms. The thereby calculated calibration factor is obtained as the mean mass per $\mathrm{Hz}$ change of all applied current densities $\left(\mathrm{ng} \cdot \mathrm{Hz}^{-1}\right.$ ) and is used for the conversion of frequency changes to mass values in the subsequent experiments.

\section{Results and discussions}

\section{Preparation and testing of the PEEK embedded lithiated gold wire reference electrodes}

Based on previous lithiation experiments from the literature $[11,14], 200 \mu \mathrm{A} \cdot \mathrm{cm}^{-2}$ current density was used to lithiate a gold wire with $250 \mu \mathrm{m}$ outer diameter. The first experiments were carried out in a commercial battery electrolyte ( $1 \mathrm{~mol} \cdot \mathrm{L}^{-1} \mathrm{LiPF}_{6}$ in EC:EMC, 3:7 by wt.). The lithiation time has been chosen to be $72 \mathrm{~h}$. However, the typical $E-t$ curves, containing the characteristic plateaus, reported in the literature for thin film electrodes could not be reproduced. Switching to a LiTFSI based electrolyte, which is widely used for lithiation experiments [14, 20,21], and trying different current densities only slightly changed the shapes of the $E-t$ curves, and well-pronounced plateaus could not be observed. The equilibrium electrode potentials (equilibrium open circuit voltages, OCV) of the wires, however, were very close to the potentials reported in [13]. Figure 1a shows typical chronopotentiometric (CP) curves obtained with gold wires in LiTFSI-based electrolyte and the subsequent OCV values for $48 \mathrm{~h}$. Even if the lithiation curves slightly differed, the equilibrium potentials of the lithiated gold wires converged to a stable value in all cases (Fig. 1b). For a gold wire having a radius of $r$ and a length of $l$ immersed into the solution, the ratio of the amounts of lithium and gold $\left(n_{\mathrm{Li}} / n_{\mathrm{Au}}\right)$ after a lithiation time $t$ with a constant current density $i$, assuming $100 \%$ faradaic efficiency (FE) and neglecting the 
Fig. 1 a Five CP curves for the lithiation of gold wires in $1 \mathrm{~mol} \cdot \mathrm{L}^{-1}$ LiTFSI containing EC:EMC (3:7 by wt.) with $200 \mu \mathrm{A} \cdot \mathrm{cm}^{-2}$ current density applied over $72 \mathrm{~h}$ and $\mathbf{b}$ OCV curves of five Au wires lithiated as in a all converging to a stable equilibrium electrode potential
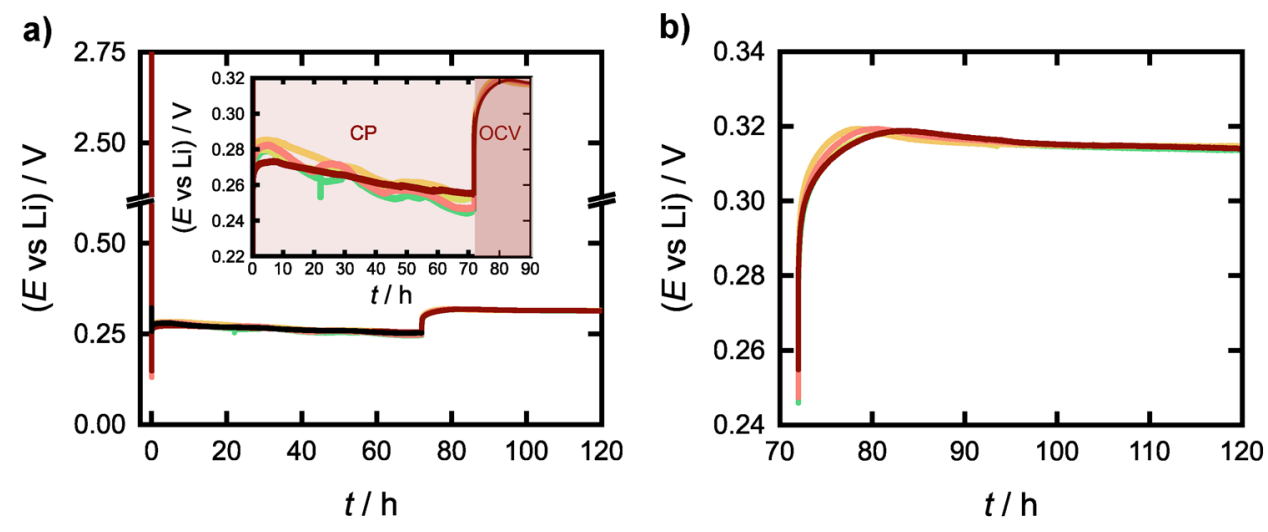

cross sectional area of the thin wire, can be calculated by the following formula:

$\frac{n_{\mathrm{Li}}}{n_{\mathrm{Au}}}=\frac{i \times 2 r \pi \times l \times t}{F} \times \frac{M_{\mathrm{Au}}}{r^{2} \pi \times l \times \rho_{\mathrm{Au}}}=\frac{2 \times i \times M_{\mathrm{Au}}}{F \times r \times \rho_{\mathrm{Au}}} \times t=k \times t$

where $F$ is the Faraday constant and $M_{\mathrm{Au}}$ and $\rho_{\mathrm{Au}}$ are the molar mass and density of gold, respectively. In our case, $k=3.4 \times 10^{-6} \mathrm{~s}^{-1}$, i.e., after $72 \mathrm{~h}$ lithiation, the ratio of the two metals in the wire is close to $1(0.9)$. Nevertheless, this ratio is enough to keep the potential of the AuLi-Ref created from such a wire constant for an extended period of time, as will be demonstrated below. However, its potential is still ca. $+310 \mathrm{mV}$ positive to $\mathrm{Li}$, which will be different for thinfilm electrodes with a much higher $n_{\mathrm{Li}} / n_{\mathrm{Au}}$ ratio.

Such lithiated $\mathrm{Au}$ wires offer many advantages for the preparation of REs: (i) their size can be flexibly varied and with that the size of the RE; (ii) they can be placed in a Luggin-capillary, as demonstrated below, in an easy manner; (iii) they offer good mechanical stability unlike thin Li wires; (iv) gold has excellent electrical conductivity and can be directly connected to the cables of the potentiostat at the free end of the wire; and (v) after proper lithiation its potential stays very stable even for long experimental times. In the following part, we discuss the preparation of PEEK housed AuLi-Refs from the wires.

For the lithiation, the gold wire is placed in a simple homemade cell filled with LiTFSI electrolyte $\left(1 \mathrm{~mol} \cdot \mathrm{L}^{-1}\right.$; EC:EMC, 3:7 by wt.). While the gold wire is operated as WE, a piece of lithium foil which is attached to a copper wire is used as the CE. The wire is lithiated with a constant current of $200 \mu \mathrm{A} \cdot \mathrm{cm}^{-2}$ according to Zhou et al. and Simon et al. [11, 14]. To ensure sufficient lithiation and avoid future potential instabilities (as is demonstrated below), the lithiation is carried out for $72 \mathrm{~h}$. After successful lithiation, the wire is transferred into a PEEK electrode body of $1.6 \mathrm{~mm}$ outer and $1 \mathrm{~mm}$ inner diameter equipped with a leak free junction at the bottom end. The PEEK electrode body is intended for aqueous use and therefore is shipped filled with an aqueous solution containing $\mathrm{H}_{2} \mathrm{SO}_{4}$ to maintain a wet junction. In order to avoid cross reactions of the acidic aqueous contents of the body with the later introduced electrolyte and lithiated wire, a thorough cleaning procedure was developed. This procedure consists of three stages with three different solvents. In the first stage, the body is repeatedly purged with water using a syringe and cleaned inside a water-filled beaker in an ultrasonication bath outside the glovebox; after that, the same steps are repeated in the second stage, this time with EtOH. After the second stage, the body is set to rest in a EtOH filled vial. In the third stage, the body is again repeatedly purged and cleaned in the sonication bath, this time with target solvent mix of EC:EMC (3:7 by wt.). After the final cleaning, the body is placed inside a sealed vial filled with EC:EMC and later introduced into the glovebox for assembly of the final electrode. Before the lithiated gold wire is introduced into the body, the body is filled with the target electrolyte depending on the electrode's desired field of use $\left(1 \mathrm{~mol} \cdot \mathrm{L}^{-1} \mathrm{LiTFSI}\right.$ or $1 \mathrm{~mol} \cdot \mathrm{L}^{-1} \mathrm{LiPF}_{6}$ in EC:EMC, 3:7 by wt.) (Fig. 2a). After that, the wire is introduced into the body (Fig. 2b). Finally, a wire end ferrule is placed on top of the body and wire. The metal part of the ferrule is crimped onto the wire to ensure electric contact, while the cavities between PEEK body and wire ferrule are sealed using a two-component epoxy resin to prevent evaporation of the electrolyte and ensure mechanical stability of the electrode (Fig. 2c). The electrode is then placed in a $1.5-\mathrm{mL}$ vial filled with the target electrolyte to prevent the junction from drying out. After complete hardening of the epoxy resin (ca. $24 \mathrm{~h}$ ), the electrode can be used.

In order to test the long-term stability of the reference electrode, it has been applied in a three electrode cell configuration containing a glassy carbon WE, a Pt wire $\mathrm{CE}$ and $10 \mathrm{mmol} \cdot \mathrm{L}^{-1}$ ferrocene (ferrocene is bis- $(\eta$ cyclopentadienyl)iron(II)) dissolved in $1 \mathrm{~mol} \cdot \mathrm{L}^{-1} \mathrm{LiTFSI}$ containing EC:EMC (3:7 by wt.). The reason of using ferrocene is first that the ferrocene $(\mathrm{Fc}) /$ ferrocenium $\left(\mathrm{Fc}^{+}\right)$ couple as a reference redox system is recommended for 
Fig. 2 Preparation steps of $1.6 \mathrm{~mm}$ PEEK housed AuLi-Ref from lithiated gold wires

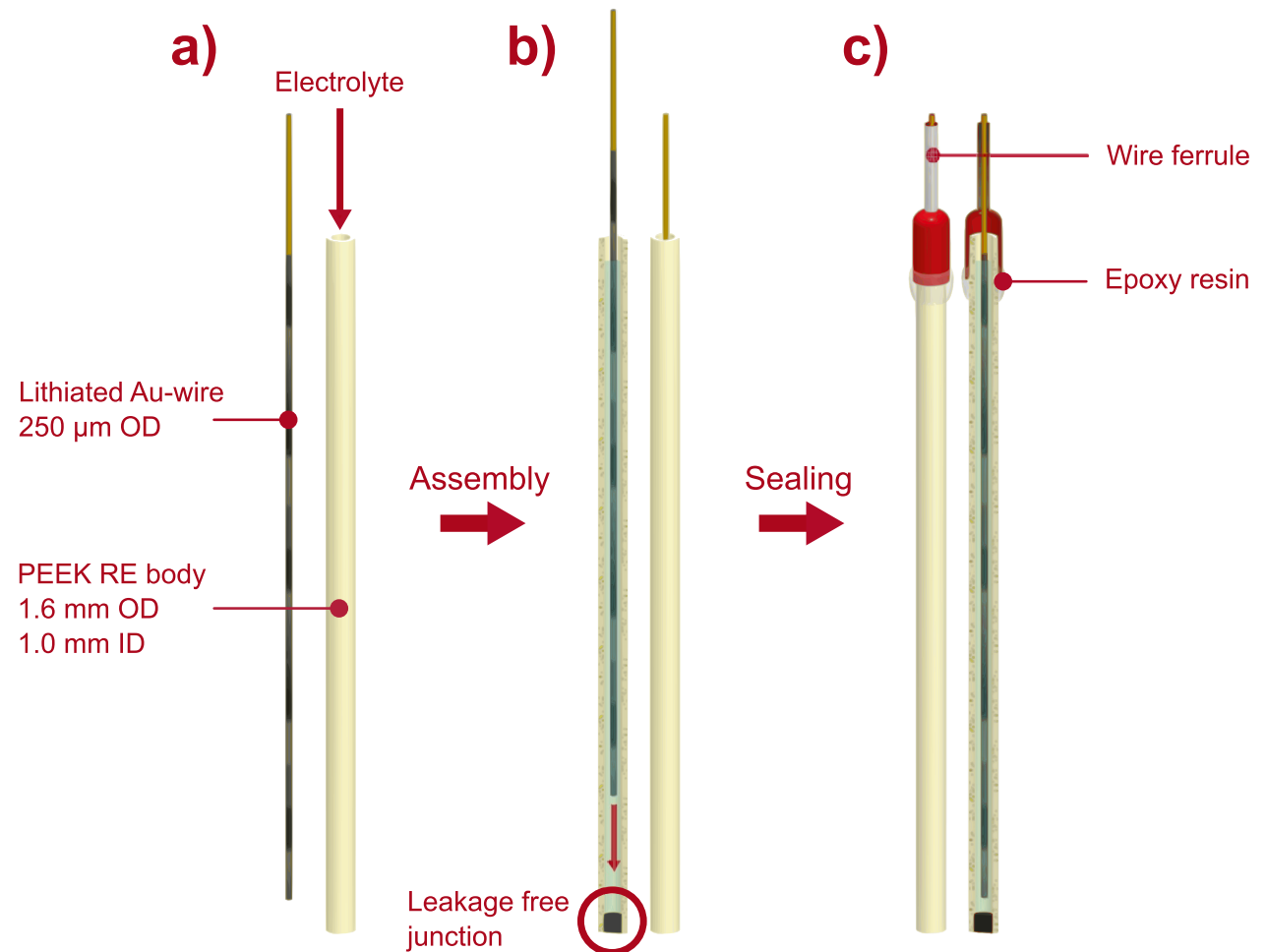

reporting electrode potentials in nonaqueous media [28]; therefore, the value of the equilibrium electrode potential of the $\mathrm{Fc} / \mathrm{Fc}^{+}$couple should be reported for the newly created RE. Second and luckily, this compound demonstrates good solubility, invariant redox potentials, and excellent chemical and electrochemical reversibility in the studied battery electrolytes. It has been shown to be a potentially useful redox reagent for the chemical overcharge protection of rechargeable lithium and lithium-ion batteries and therefore has been studied in detail by Laoire et al. [29]. The authors studied the kinetics of oxidation of $\mathrm{Fc}_{\mathrm{c}} \mathrm{Fc}^{+}$ in the non-aqueous lithium ion conducting electrolyte composed of a solution of $1 \mathrm{~mol} \cdot \mathrm{L}^{-1} \mathrm{LiPF}_{6}$ in $\mathrm{EC}: \mathrm{EMC}$
(1:1 by vol.) solvent mixture and concluded that the $\mathrm{Fc} /$ $\mathrm{Fc}^{+}$redox couple is reversible even in this highly concentrated electrolyte.

Figure 3 a demonstrates this excellent reversibility with a cyclic voltammogram obtained in $10 \mathrm{mmol} \cdot \mathrm{L}^{-1} \mathrm{Fc}$ containing LiTFSI-based electrolyte. The long-term stability has been checked by carrying out cyclic voltammetric experiments every $1 \mathrm{~h}$ in the above-described cell. The half wave potential $E_{1 / 2}$ has been determined from each $\mathrm{CV}$ curve from the anodic $\left(E_{\mathrm{pa}}\right)$ and cathodic $\left(E_{\mathrm{pc}}\right)$ peak potentials using a homemade software with regard to the huge number of CVs. The $E_{1 / 2}$ values were estimated as $1 / 2\left(E_{\mathrm{pa}}+E_{\mathrm{pc}}\right)$. Figure $3 \mathrm{~b}$ shows the change of $E_{1 / 2}$ directly after preparation a)

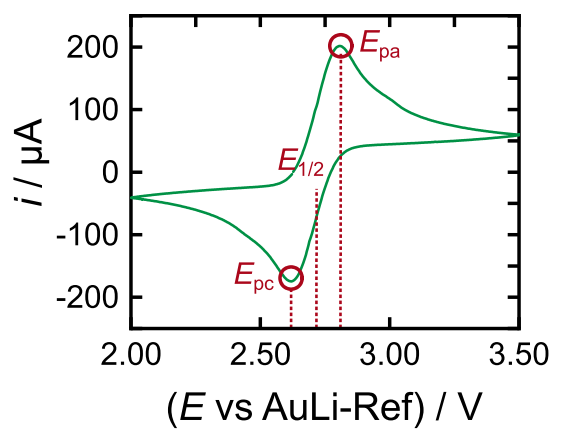

b)

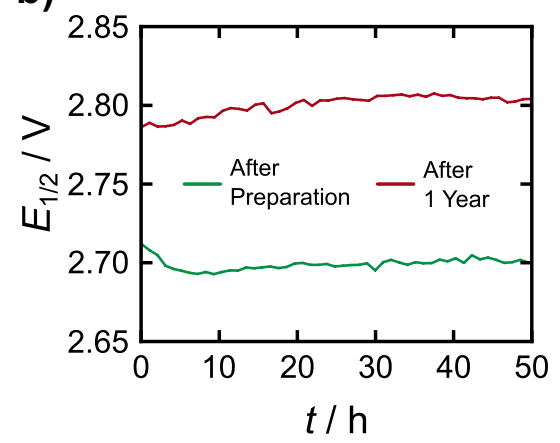

c)

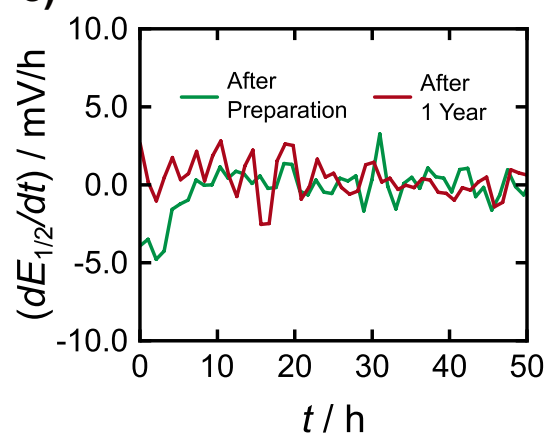

Fig. 3 a Cyclic voltammetric response of ferrocene $\left(10 \mathrm{mmol} \cdot \mathrm{L}^{-1}\right.$ in $1 \mathrm{~mol} \cdot \mathrm{L}^{-1} \mathrm{LiTFSI}$ containing EC:EMC $(3: 7 \mathrm{by} \mathrm{wt})$ with $100 \mathrm{mV} \cdot \mathrm{s}^{-1} \mathrm{scan}$ rate and $\mathbf{b}, \mathbf{c}$ stability of potential over time 
of the AuLi-Ref (dark green curve) and after 1 year of use (dark red curve). The value of $E_{1 / 2}$ shifted ca. $100 \mathrm{mV}$ in one year. The change of $E_{1 / 2}$ within the timeframe of $50 \mathrm{~h}$ can be estimated by deriving the $E_{1 / 2}(t)$ function and is displayed in Fig. 3c. The values are in the lower $\mathrm{mV} / \mathrm{h}$ range and therefore exhibit better potential stability than common Li-foil REs (see Fig. S1). Here we would like to note that we used the original $E_{1 / 2}(t)$ function for the derivation without smoothing the curve in advance. To be able to account even for these minimal changes in the potential of the AuLi-Ref, we always check its potential with the $\mathrm{Fc} / \mathrm{Fc}^{+}$redox couple both before and after the actual measurements.

\section{Lithiation of Au films - insights into potential stability}

The potential stability of lithiated Au electrodes can be investigated using thin film $(100 \mathrm{~nm})$ Au deposited onto quartz. The
CP lithiation curves showed the characteristic shape, known from the literature in both electrolytes. Figure 4 shows the results of measurement sequences consisting of a $\mathrm{CP}$ part with $200 \mu \mathrm{A} \cdot \mathrm{cm}^{-2}$ for $4 \mathrm{~h}$ followed by an OCV period for $40 \mathrm{~h}$. The potential values are IR corrected values, using the current interruption method for $50 \mathrm{~ms}$, after the CP part. The first two potential plateaus shown in the insets of Fig. $4 \mathrm{a}$ and $\mathrm{b}$ belong to phase transformations of the $\mathrm{Li}_{\mathrm{x}} \mathrm{Au}_{\mathrm{y}}$ alloys. In the first step of alloying, Bach et al. found a hexagonal structure with composition $\mathrm{Li}_{5} \mathrm{Au}_{3}$ [21]. The second plateau corresponds to the thermodynamically stable $\mathrm{Li}_{3} \mathrm{Au}$ phase with face centered cubic structure. The second plateau ends at ca. $4000 \mathrm{~s}$ and is followed by the deposition of metallic lithium onto the formed alloy. In case of the thin Au film the $n_{\mathrm{Li}} / n_{\mathrm{Au}}$ ratio as function of lithiation time can be determined by the formula:

$\frac{n_{\mathrm{Li}}}{n_{\mathrm{Au}}}=\frac{i \times r^{2} \pi \times t}{F} \times \frac{M_{\mathrm{Au}}}{r^{2} \pi \times h \times \rho_{\mathrm{Au}}}=\frac{i \times M_{\mathrm{Au}}}{F \times h \times \rho_{\mathrm{Au}}} \times t=k^{\prime} \times t$
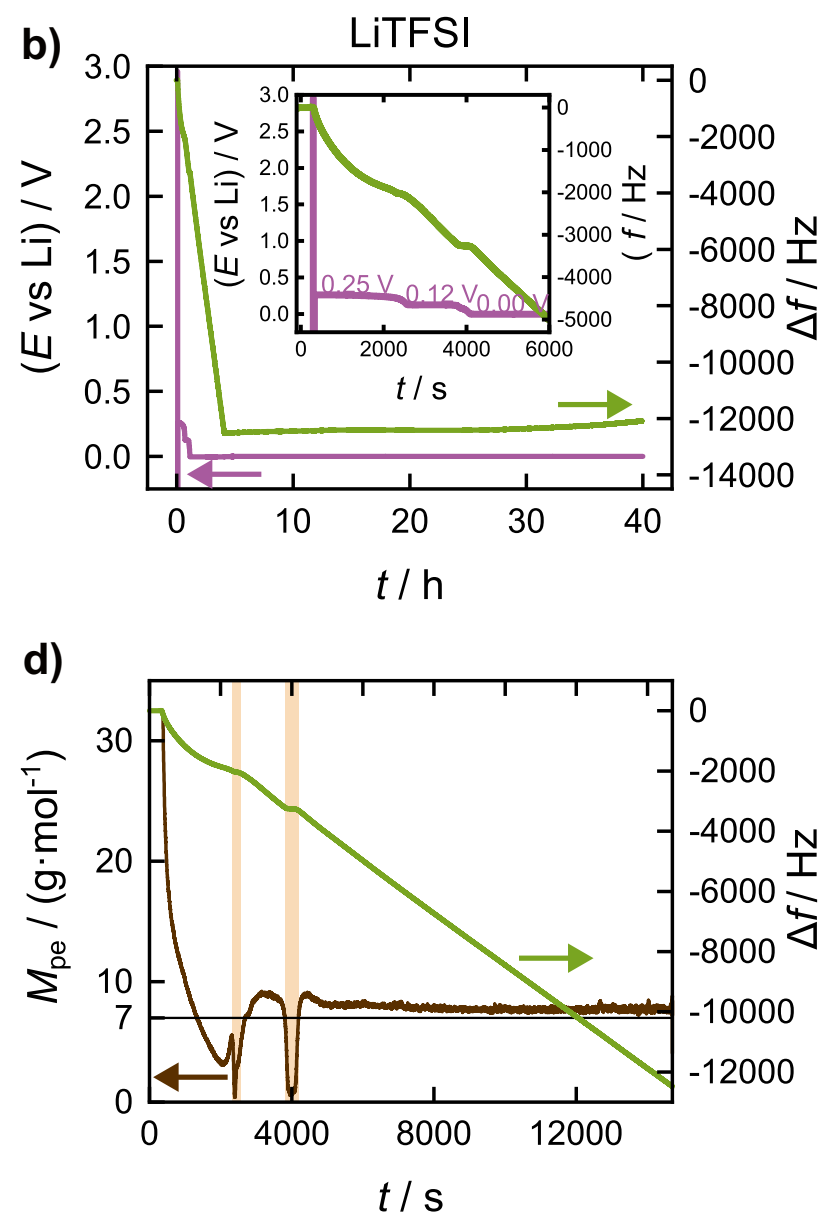

ured frequency change data (green curves). Apparent molar masses calculated from the frequency change data during the galvanostatic lithiation experiments for $\mathbf{c} \mathrm{LiPF}_{6}$ and $\mathbf{d}$ LiTFSI-based electrolytes 
where $h$ is the height of the gold film $(h=100 \mathrm{~nm})$ and the side area of the cylinder has been neglected. In this case $k^{\prime}=2.1 \times 10^{-3} \mathrm{~s}^{-1}$; i.e., after ca. $473 \mathrm{~s}$, the $n_{\mathrm{Li}} / n_{\mathrm{Au}}=1$ ratio is achieved. Although the length of the plateaus is not well correlated to this value (formation of $\mathrm{Li}_{3} \mathrm{Au}$ would need ca. 1418 s), it can be seen in Fig. 4 that for both electrolytes, a stable potential of the lithiated Au electrode is achieved under these conditions. The reason for the huge discrepancy between the calculated lithiation times and observed length of plateaus is most probably the invalidity of the assumption that lithium deposition occurs with $100 \% \mathrm{FE}$. At this point, the analysis of the simultaneously measured EQCM data greatly helps in the explanation.

Very interestingly, the frequency change curves (green lines in Fig. 4) also reflect the formation of the different alloy phases: the rate of frequency (i.e., mass) change decreases towards the end of the potential plateaus, i.e., towards the completeness of the stable phase and remains constant for the rest of the lithiation time (from ca. $4000 \mathrm{~s}$ to $4 \mathrm{~h}$ ). It is possible to calculate apparent molar masses from the measurements after calibration and assuming the validity of the Sauerbrey-equation [22], which states that the frequency change is directly proportional to the mass change $(\Delta f \propto-\Delta m)$. It should be noted that especially due to the formation of a possibly non-rigidly attached SEI at the crystal's surface, the applicability of the Sauerbrey-equation is not given without restrictions. The good agreement of theoretical and calculated mass change values, however, validates its use in this situation and also provides a clear basis for following calculations. We have carried out the calibration of the EQCM cell by using $0.1 \mathrm{~mol} \cdot \mathrm{L}^{-1} \mathrm{AgClO}_{4}$ dissolved in the battery electrolytes. $\mathrm{AgClO}_{4}$ dissolves very slowly, and to reach a concentration of $0.1 \mathrm{~mol} \cdot \mathrm{L}^{-1}$, solutions were left overnight to dissolve. Surprisingly, the value of the integral sensitivity of the crystals was very close to the theoretical one for LiTFSI-based electrolytes $\left(17.3 \mathrm{ng} \cdot \mathrm{Hz}^{-1} \cdot \mathrm{cm}^{-2}\right.$ calculated vs. $17.7 \mathrm{ng} \cdot \mathrm{Hz}^{-1} \cdot \mathrm{cm}^{-2}$ theoretical), while the difference for the $\mathrm{LiPF}_{6}$-based electrolyte was somewhat bigger (14.9 ng. $\mathrm{Hz}^{-1} \cdot \mathrm{cm}^{-2}$ calculated). Although $\mathrm{PF}_{6}^{-}$is supposed to be a weakly coordinating anion, it seems to interact strongly to the Au surface to hinder the deposition of $\mathrm{Ag}$ (we can rule out competing electrode reactions at the potential of $\mathrm{Ag}$ deposition, which is ca. $3.8 \mathrm{~V}$ vs. $\mathrm{Li}$ ). Apparent molar masses or $M_{\mathrm{pe}}$ (mass per electron) values have been calculated for the lithiation experiments and are shown in Fig. $4 \mathrm{c}$ and d. The curves are the derivatives of the corresponding $m=m(Q / F)$ functions and are smoothed by adjacent averaging taking 50 adjacent points for the sake of better visibility.

It is evident from the change of the $M_{\mathrm{pe}}$ values, which decrease asymptotically after applying the constant lithiation current that first an SEI is being built on the electrode resulting in $M_{\mathrm{pe}}>>7 \mathrm{~g} \cdot \mathrm{mol}^{-1}$. At the end of the potential plateaus, the $M_{\mathrm{pe}}$ is close to zero, i.e., no mass change, neither related to SEI formation nor to Li intercalation accompanies these phase transformations. In the last phase of the 4-h long deposition starting at ca. $4000 \mathrm{~s}$ and for the rest of the CP period, the $M_{\mathrm{pe}}$ is very close to $7 \mathrm{~g} \cdot \mathrm{mol}^{-1}$ (the horizontal line at the figure is a constant function at $7 \mathrm{~g} \cdot \mathrm{mol}^{-1}$ ) for the LiTFSI-based electrolyte. The total frequency change (green line) is ca. half as much for the $\mathrm{LiPF}_{6}$ based electrolyte as for the LiTFSI-based electrolyte (ca. $95.9 \mu \mathrm{g}$ for $\mathrm{LiPF}_{6}$ vs. ca. $216.2 \mu \mathrm{g}$ for LiTFSI) at same applied current density until the end of the lithiation. The reason for this is most probably the different SEI structure for the two electrolytes. Therefore, we can say that while both Au electrodes - lithiated in the two different electrolytes - will exhibit stable potentials over a prolonged period of time, it seems that Li deposition happens more readily through an SEI built up in LiTFSI. This difference in SEI build up has also a huge influence on the long-term potential stability of lithiated Au electrodes prepared in the two electrolytes with shorter lithiation times as will be demonstrated below.

\section{Short-term lithiation — insights into the properties of SEI}

In order to see how the potential stability of lithiated $\mathrm{Au}$ electrodes is influenced by lithiation times, experiments with CPs for only $1000 \mathrm{~s}$ instead of $4 \mathrm{~h}$ have been conducted (Fig. 5). Although after $1000 \mathrm{~s}$ lithiation, a theoretical $n_{\mathrm{Li}} / n_{\mathrm{Au}}$ ratio of ca. 2 is achieved; in both cases, the $E$ vs $t$ curves do not stay constant and rapidly change most probably after the spontaneous delithiation of gold under OCV conditions. This is less surprising if considering that completion of the lithium alloy formation is only achieved after ca. $1400 \mathrm{~s}$. Interestingly, however, the mass of the electrode in $\mathrm{LiPF}_{6}$ decreases first right after the $\mathrm{CP}$ period and stays more or less constant for LiTFSI. It increases for both electrolytes as the potential starts to rapidly increase. Figure 5 demonstrates an important difference between the two electrolytes: the potential stays stable for more than $30 \mathrm{~h}$ in LITFSI and for only ca. $10 \mathrm{~h}$ in $\mathrm{LiPF}_{6}$. We speculate that the initial mass loss for $\mathrm{LiPF}_{6}$ is not related to lithium loss, since as we described above, the $\mathrm{LiPF}_{6}$ type SEI does not facilitate $\mathrm{Li}$ transfer as much as the LiTFSI type and the potential also stays in this phase rather constant. Maybe the inner inorganic SEI layer [30] is being dissolved in lack of a thicker and protective organic SEI in this region. However, this problem needs further investigations to be able to convincingly prove our speculation. The delithiation happens as the potential increases. In this phase, $\mathrm{Li}$ is being oxidized and electrolyte reduced and deposited onto the electrode, causing the mass 

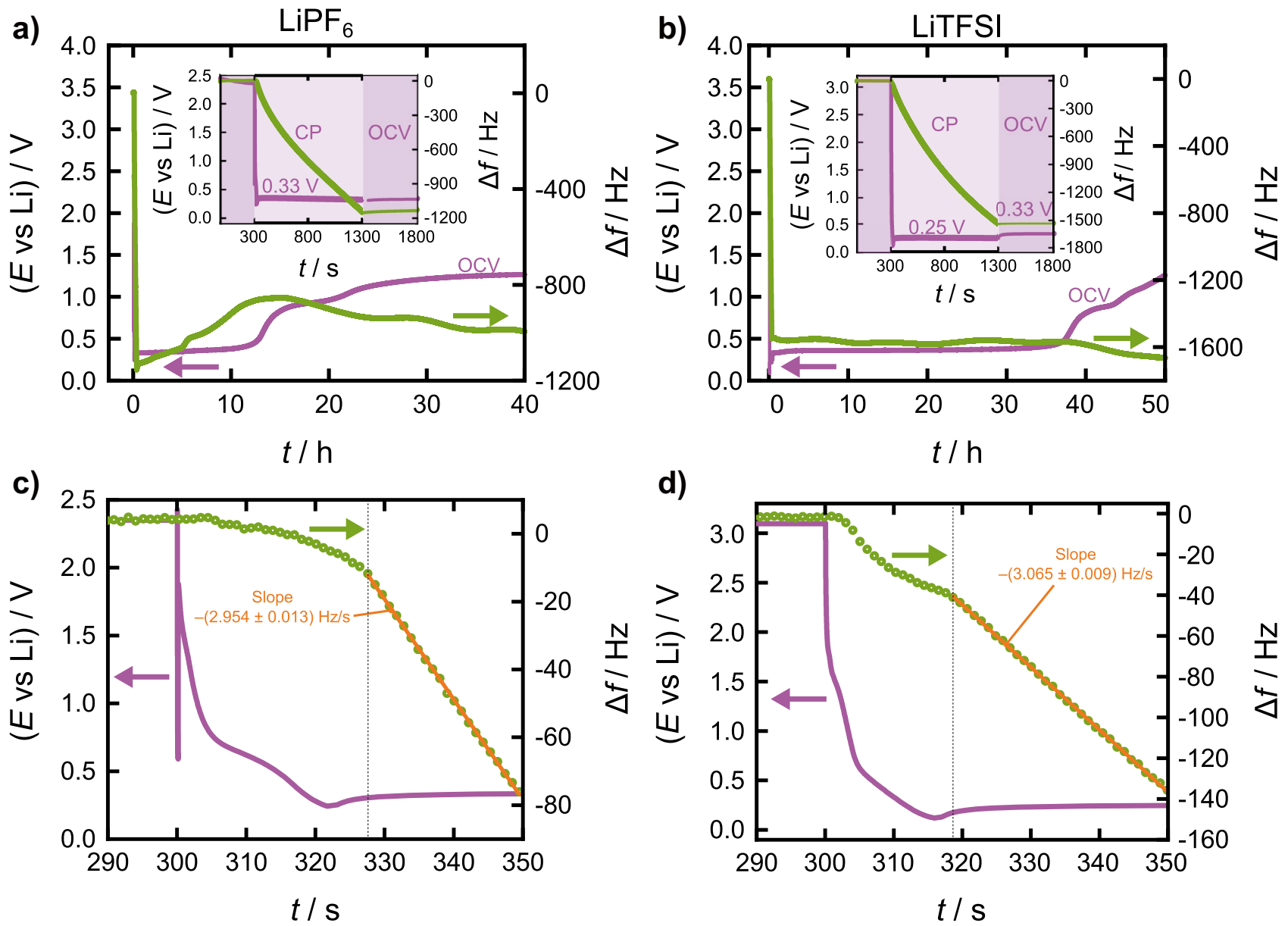

d)

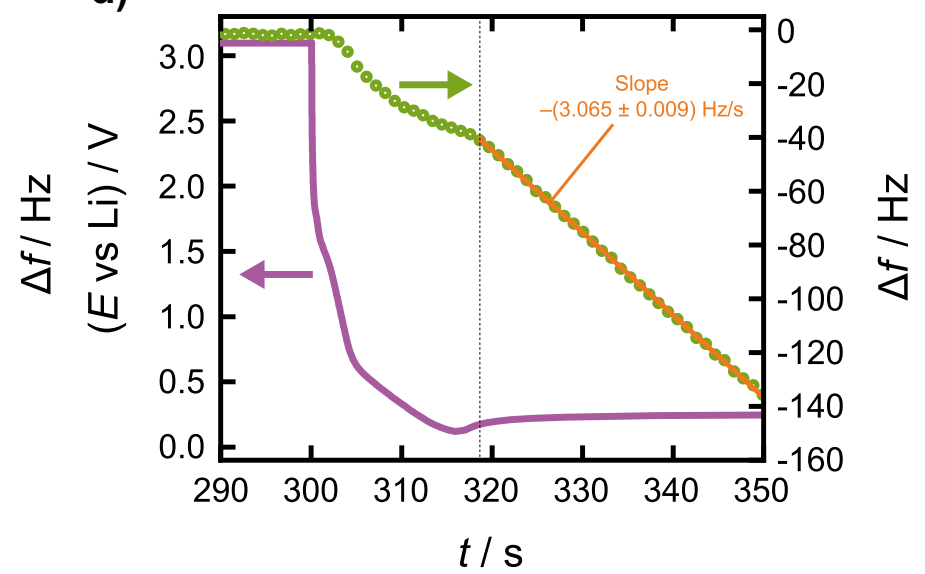

Fig. 5 Lithiation of 100-nm-thick Au EQCM electrodes for $1000 \mathrm{~s}$ in a $1 \mathrm{~mol} \cdot \mathrm{L}^{-1} \mathrm{LiPF}_{6}$ containing EC:EMC (3:7) and b $1 \mathrm{~mol} \cdot \mathrm{L}^{-1} \mathrm{LiTFSI}$ containing EC:EMC (3:7) with $200 \mu \mathrm{A} \cdot \mathrm{cm}^{-2}$ current density with the subsequent $\mathrm{OCV}$ periods and simultaneously measured frequency

increase in both cases. These results demonstrate that lithiated gold electrodes will suffer potential instability on the long term if not enough $\mathrm{Li}$ is deposited onto the electrode.

Before the first plateau, as shown in Fig. 5c and d, a potential dip can be observed between 310 and $330 \mathrm{~s}$. This is in accordance with previous observations [21]. The use of EQCM provides a better insight into the initial reactions. Right after the application of the constant current, the rate of frequency change is less than half of that registered for the first plateau and showed by the fitted linear curves. Therefore, we speculate that this initial phase showing potential shoulders and a dip is rather related to the reductive decomposition of the electrolyte, i.e., the formation of the SEI and maybe to the initial nucleation of $\mathrm{Li}$ on $\mathrm{Au}$. Zhang et al. [31] showed that the SEI formation takes place through two major stages in case of graphite anodes. The first stage takes place before lithiation of graphite, during which a loose and highly resistive film is formed. The second stage occurs at a narrow voltage range of $0.25-0.04 \mathrm{~V}$, which proceeds

change data (green curves) demonstrating the instability of OCV values. The initial $50 \mathrm{~s}$ after the application of the constant current together with the rate of frequency changes are shown in $\mathbf{c}$ for $\mathrm{LiPF}_{6}$ and $\mathbf{d}$ for LiTFSI based electrolytes

simultaneously with lithiation of graphite electrode. The authors found that "in the second stage, a stable, compact, and highly conductive SEI film is produced." When looking at the frequency change curves between 300 and $320 \mathrm{~s}$ also two kinds of stages can be identified. However, whereas this first phase can be characterized in $\mathrm{LiPF}_{6}$-based electrolyte with a concave function, in LiTFSI-based electrolyte, a convex function is observed. After this ca. 20-30 s, the lithiation rate becomes constant and will decrease again only towards the end of the first potential plateau (see Fig. 4). It is also apparent that in the initial two stages of lithiation (alloy formation), the differences between the deposited mass for $\mathrm{LiPF}_{6}$ and LiTFSI are marginal. Only during the deposition of lithium, i.e., after the alloy formation is finished, differ the frequency change rates substantially.

We carried out lithiation with wire type Au electrodes, too, that also showed the instability of the potential after an extended OCV period. In the delithiation rate, the surface area over volume ratio might play an important role, if the 
charge transfer is the rate determining step. In case of the thin films, this is proportional to the inverse of the layer thickness, whereas for wires to the inverse of the wire's diameter. In our case, there are at least three orders of magnitude differences between these two ratios for the thin films and wires that reflect in the slower delithiation rate of the wires. It can be concluded that the SEI facilitates the deposition/insertion of Li in general.

During cyclic voltammetric experiments (CVs), the aforementioned differences in the SEI forming properties of the two electrolytes can be investigated in more detail. In both cases, a new gold crystal is taken for the experiments and the electrodes are polarized with $5 \mathrm{mV} \cdot \mathrm{s}^{-1}$ scan rate from their $\mathrm{OCV}$ to cathodic directions. In the $\mathrm{LiPF}_{6}$-based electrolyte, first, the frequency increases slightly (Fig. 6a), maybe due to the repulsion of the adsorbed $\mathrm{PF}_{6}{ }^{-}$anions from the surface as the potential decreases. However, the frequency starts to decrease already at around $2.1 \mathrm{~V}$ and a sharp cathodic peak appears at this potential. This cathodic peak corresponds to the reduction of dissolved oxygen in the electrolyte and disappears in the second cycle [32]. The frequency change is in good agreement with the work of Yamamoto et al. [24], who investigated the deposition processes in $\mathrm{LiClO}_{4}$ containing tetraethylammonium perchlorate dissolved in propylene carbonate. The authors did not observe any substantial mass change without the addition of $\mathrm{LiClO}_{4}$ to the solution; therefore, they concluded that Li containing species are deposited onto the surface. The rate of frequency decrease, i.e., mass increase, is the highest in the following potential region that refers to the decomposition of the electrolyte. Interestingly, the deposited layer retards the rate of deposition at lower potentials that suggests that an electrically resistive layer is forming. As we have already seen in the course of the galvanostatic measurements, this SEI layer also progressively decelerates the rate of Li deposition onto Au compared to LiTFSI (see the frequency change curves in Fig. 4a and b). The second cathodic peak corresponds to the reduction of trace amounts of water in the electrolyte. After this peak, the rate of frequency change becomes smaller. The potential has been reversed at $0.4 \mathrm{~V}$ vs. $\mathrm{Li}$ to avoid the underpotential deposition of Li onto Au [23]. Upon potential reversal, the mass increase continues in the anodic scan until the OCV potential is reached again and the current remains in the cathodic region at around $-50 \mathrm{nA} \cdot \mathrm{cm}^{-2}$. The frequency change is irreversible and finally accounts to ca. $180 \mathrm{~Hz}$ mass increase. Since the measured currents are in the $\mathrm{nA}$ range, the charge passed through the electrode is also minimal compared to the large frequency changes. After converting the frequency changes to mass changes using the coefficient determined from calibration, apparent molar masses are in the range of $>1000 \mathrm{~g} \cdot \mathrm{mol}^{-1}$, referring to mainly chemical reactions causing the deposit on the surface rather than electrochemical.

Contrary to $\mathrm{LiPF}_{6}$, no oxygen reduction peak can be observed in the LiTFSI-based electrolyte (Fig. 6b). The absence of this peak could either originate from varying oxygen levels of the electrolytes caused by the manufacturer or differences (i.e., inhibition) in the oxygen reduction mechanism in the presence of $\mathrm{TFSI}^{-}$anions. The overall frequency change for this LiTFSI electrolyte is very moderate down
Fig. $6 \mathrm{CV}$ measurements (red curves) with 100 -nm-thick Au EQCM electrodes using a $1 \mathrm{~mol} \cdot \mathrm{L}^{-1} \mathrm{LiPF}_{6}$ containing EC:EMC (3:7) and $\mathbf{b}$ $1 \mathrm{~mol} \cdot \mathrm{L}^{-1}$ LiTFSI containing EC:EMC (3:7) with a scan rate of $5 \mathrm{mV} \cdot \mathrm{s}^{-1}$ and simultaneously measured frequency change data (green curves). The lower potential limit was $0.4 \mathrm{~V}$ for $\mathrm{LiPF}_{6}$ and $0.15 \mathrm{~V}$ for LiTFSIbased electrolytes

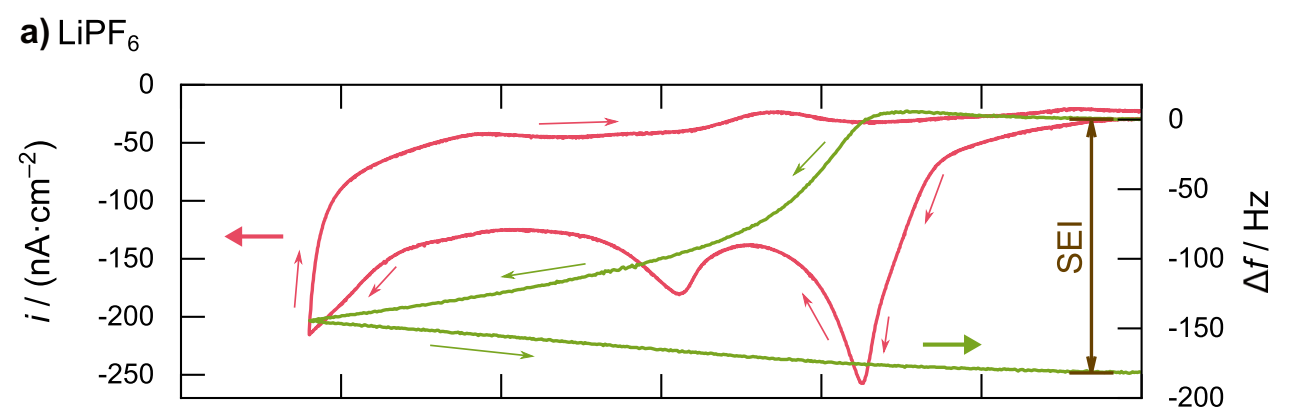

b) LiTFSI

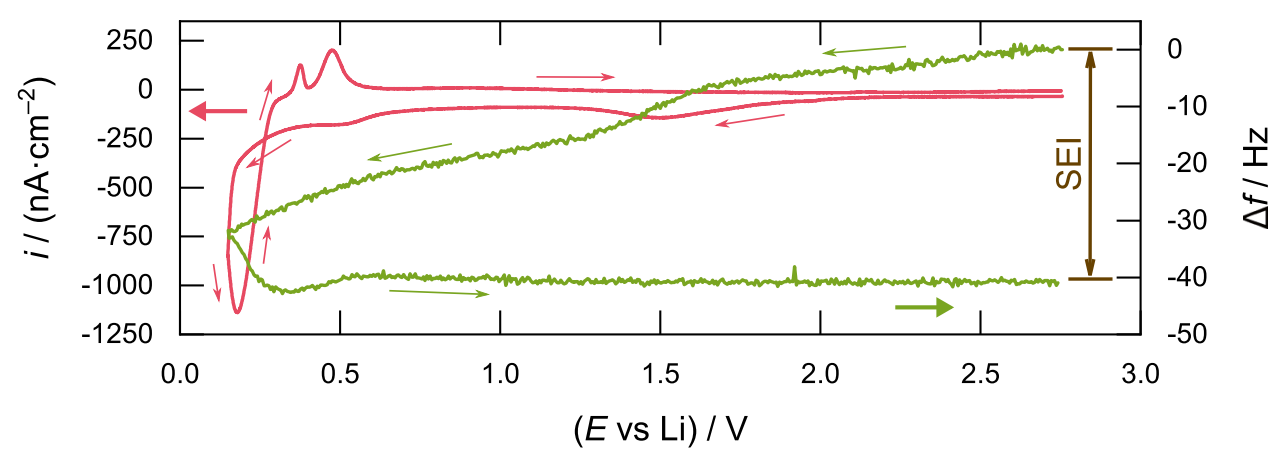


to $0.5 \mathrm{~V}$ compared to $\mathrm{LiPF}_{6}$. Another difference is that the rate of frequency change never decreases until the potential reversal of $0.15 \mathrm{~V}$, which refers to an SEI with good electrical conductivity. This potential limit was chosen because of the very steep increase in current, which starts at around ca. $0.17 \mathrm{~V}$ vs $\mathrm{Li}$ and is related to the underpotential deposition (UPD) of Li [32] (simultaneously to ongoing SEI formation as the frequency change curve shows). Most probably the deposited $\mathrm{Li}$ initiates a faster buildup of the SEI. Upon potential reversal, two anodic peaks appear at around $0.4 \mathrm{~V}$ and $0.5 \mathrm{~V}$, that are related to the oxidation of Li. Parallel to these processes, the frequency increases and stabilizes after the peaks. We speculate that the two peaks are the result of oxidation of energetically two different kinds of $\mathrm{Li}: \mathrm{Li}$ deposited onto $\mathrm{Au}$ and already alloyed with $\mathrm{Au}$. From the frequency change curve, it seems that the irreversible change corresponds to the formed SEI (around $40 \mathrm{~Hz}$ ) and the rest of the reversible change to the electrochemical oxidation of Li. Compared to $\mathrm{LiPF}_{6}$, it seems that LITFSI forms less SEI in the same potential range; however, the SEI formed from LiTFSI-based electrolyte has beneficial properties towards the deposition of $\mathrm{Li}$ onto $\mathrm{Au}$ (see also Fig. 4). This might have some implications also for graphite electrodes and on the intercalation/deintercalation kinetics of $\mathrm{Li}$, which needs, however, further studies.

\section{Conclusions}

We have examined the electrochemical lithiation of gold in two different kind of electrolytes in form of wires and thin films with the aim to build stable reference electrodes with well-defined mechanical properties. Gold wires after $72 \mathrm{~h}$ of lithiation with a current density of $200 \mu \mathrm{A} \cdot \mathrm{cm}^{-2}$ showed excellent electrochemical stability over a prolonged test period and are highly suitable to build PEEK embodied reference electrodes with variable mechanical properties. These electrodes also showed outstanding potential stability not only over the course of several days but also over an entire year. Experiments with thin film Au electrodes in form of coated EQCM crystals provided insights into the effects of varying lithiation times and electrolytes. While too short lithiation times will result in unstable potentials, also, the use of $\mathrm{LiPF}_{6}$ will result in lower potential stability compared to LiTFSI-based electrolytes. The EQCM measurements also revealed differences in the kinetics of lithiation of thin film Au compared to wired type Au electrodes. Well-pronounced potential plateaus appeared on the chronopotentiometric curves, and the simultaneously measured frequency change curves also show the changing lithiation kinetics towards the ends of the potential plateaus. These frequency change curves could also explain the large differences between the two electrolytes. Whereas the total mass change until the completion of formation of the stoichiometric $\mathrm{Li}-\mathrm{Au}$ alloy is roughly the same for the two electrolytes, compared to $\mathrm{LiPF}_{6}$, the amount of deposited lithium after $4 \mathrm{~h}$ is more than double in LiTFSI-based electrolyte. The calculation of apparent molar mass values reflects a relatively fast buildup of the SEI that is followed by a period in which nearly exclusively $\mathrm{Li}$ is deposited. The differences of the two types of SEI layers that are already revealed in the frequency change curves and also reflected during first $\mathrm{CV}$ cycles are the most probable reason for this huge difference in the lithiation behavior of the different electrolytes.

Supplementary information The online version contains supplementary material available at https://doi.org/10.1007/s10008-021-05060-3.

Acknowledgements The authors acknowledge I. Szendrő from MicroVacuum Ltd. (Budapest, Hungary) for providing us with their new eQCM-I Mini System for testing for the here described study.

Funding Open Access funding enabled and organized by Projekt DEAL

Availability of data and material All experimental data is available upon request from the authors.

\section{Declarations}

Conflict of interest The authors declare no competing interests.

Open Access This article is licensed under a Creative Commons Attribution 4.0 International License, which permits use, sharing, adaptation, distribution and reproduction in any medium or format, as long as you give appropriate credit to the original author(s) and the source, provide a link to the Creative Commons licence, and indicate if changes were made. The images or other third party material in this article are included in the article's Creative Commons licence, unless indicated otherwise in a credit line to the material. If material is not included in the article's Creative Commons licence and your intended use is not permitted by statutory regulation or exceeds the permitted use, you will need to obtain permission directly from the copyright holder. To view a copy of this licence, visit http://creativecommons.org/licenses/by/4.0/.

\section{References}

1. Inzelt G, Lewenstam A, Scholz F (2013) Handbook of reference electrodes. Springer, Berlin Heidelberg, Berlin, Heidelberg

2. La Mantia F, Wessells CD, Deshazer HD, Cui Y (2013) Reliable reference electrodes for lithium-ion batteries. Electrochem Commun 31:141-144

3. Costard J, Ender M, Weiss M, Ivers-Tiffée E (2016) Threeelectrode setups for lithium-ion batteries. J Electrochem Soc 164:A80-A87

4. Waldmann T, Hogg B-I, Kasper M, Grolleau S, Couceiro CG, Trad K, Matadi BP, Wohlfahrt-Mehrens M (2016) Interplay of operational parameters on lithium deposition in lithium-ion cells: systematic measurements with reconstructed 3-electrode pouch full cells. J Electrochem Soc 163:A1232-A1238 
5. Barsoukov E (1999) Kinetics of lithium intercalation into carbon anodes: in situ impedance investigation of thickness and potential dependence. Solid State Ionics 116:249-261

6. Ender M, Weber A, Ellen I-T (2011) Analysis of three-electrode setups for AC-impedance measurements on lithium-ion cells by FEM simulations. J Electrochem Soc 159:A128-A136

7. Dees DW, Jansen AN, Abraham DP (2007) Theoretical examination of reference electrodes for lithium-ion cells. J Power Sources 174:1001-1006

8. Wandt J, Lee J, Arrigan DWM, Silvester DS (2018) A lithium iron phosphate reference electrode for ionic liquid electrolytes. Electrochem Commun 93:148-151

9. Gómez-Cámer JL, Novák P (2013) Electrochemical impedance spectroscopy: Understanding the role of the reference electrode. Electrochem Commun 34:208-210

10. Verbrugge MW, Baker DR, Koch BJ (2002) Mathematical modeling of high-power-density insertion electrodes for lithium ion batteries. J Power Sources 110:295-309

11. Zhou J, Notten PHL (2004) Development of reliable lithium microreference electrodes for long-term in situ studies of lithiumbased battery systems. J Electrochem Soc 151:A2173-A2179

12. Abraham DP, Poppen SD, Jansen AN, Liu J, Dees DW (2004) Application of a lithium-tin reference electrode to determine electrode contributions to impedance rise in high-power lithium-ion cells. Electrochim Acta 49:4763-4775

13. Solchenbach S, Pritzl D, Kong EJY, Landesfeind J, Gasteiger HA (2016) A gold micro-reference electrode for impedance and potential measurements in lithium ion batteries. J Electrochem Soc 163:A2265-A2272

14. Simon FJ, Blume L, Hanauer M, Sauter U, Janek J (2018) Development of a wire reference electrode for lithium all-solid-state batteries with polymer electrolyte: FEM simulation and experiment. J Electrochem Soc 165:A1363-A1371

15. Aurbach D, Moshkovich M, Cohen Y, Schechter A (1999) The study of surface film formation on noble-metal electrodes in alkyl carbonates/li salt solutions, using simultaneous in situ AFM, EQCM, FTIR, and EIS. Langmuir 15:2947-2960

16. Dey AN (1971) Electrochemical Alloying of Lithium in Organic Electrolytes. J Electrochem Soc 118:1547

17. Ranninger J, Wachs SJ, Möller J, Mayrhofer KJJ, Berkes BB (2020) On-line monitoring of dissolution processes in nonaqueous electrolytes - a case study with platinum. Electrochem Commun 114:106702

18. Ranninger J, Mayrhofer KJJ, Berkes BB (2021) The crucial role of water in the stability and electrocatalytic activity of Pt electrodes. J Phys Chem C 125:13254-13263

19. Wachs SJ, Behling C, Ranninger J, Moeller J, Mayrhofer KJJ, Berkes BB (2021) Online monitoring of the transition metal dissolution from a high Ni content cathode material. Mater Interfaces in press, accepted, ACS Appl

20. Bach P, Stratmann M, Valencia-Jaime I, Romero AH, Renner FU (2015) Lithiation and delithiation mechanisms of gold thin film model anodes for lithium ion batteries: electrochemical characterization. Electrochim Acta 164:81-89

21. Bach P, Valencia-Jaime I, Rütt U, Gutowski O, Romero AH, Renner FU (2016) Electrochemical lithiation cycles of gold anodes observed by in situ high-energy X-ray diffraction. Chem Mater 28:2941-2948

22. Inzelt G (2010) Electrochemical Quartz Crystal Nanobalance, Chapter II.10, pp. 257-269 In F. Scholz (ed) Electroanalytical methods: guide to experiments and applications, 2nd edn. Springer, Berlin Heidelberg, Berlin, Heidelberg

23. Aurbach D, Zaban A (1995) The use of EQCM for the study of nonactive metal electrodes in propylene carbonate - LiAsF6 solutions: significance of the data obtained. J Electrochem Soc 142:L108-L111

24. Yamamoto N, Hirasawa H, Ishida H, Tatsuma T, Oyama N (1994) Electrochemical deposition and dissolution processes of lithium compound on gold from propylene carbonate. Bull Chem Soc Jpn 67:1296-1300

25. Koike S, Fujieda T, Wakabayashi N, Higuchi S (1997) Electrochemical and quartz microbalance technique studies of anode material for secondary lithium batteries. J Power Sources 68:480-482

26. Shpigel N, Levi MD, Sigalov S, Daikhin L, Aurbach D (2018) In situ real-time mechanical and morphological characterization of electrodes for electrochemical energy storage and conversion by electrochemical quartz crystal microbalance with dissipation monitoring. Acc Chem Res 51:69-79

27. Zhu D, Fan H, Wang H (2021) PF6-intercalation into graphite electrode from propylene carbonate. ACS Appl Energy Mater 4:2181-2189

28. Gritzner G, Kuta J (1984) Recommendations on reporting electrode potentials in nonaqueous solvents (Recommendations 1983). Pure Appl Chem 56:461-466

29. Laoire CO, Plichta E, Hendrickson M, Mukerjee S, Abraham KM (2009) Electrochemical studies of ferrocene in a lithium ion conducting organic carbonate electrolyte. Electrochim Acta $54: 6560-6564$

30. Aurbach D (2000) Review of selected electrode-solution interactions which determine the performance of $\mathrm{Li}$ and $\mathrm{Li}$ ion batteries. J Power Sources 89:206-218

31. Zhang S, Ding MS, Xu K, Allen J, Jow TR (2001) Understanding solid electrolyte interface film formation on graphite electrodes. Electrochem Solid-State Lett 4:A206-A208

32. Aurbach D, Daroux M, Faguy P, Yeager E (1991) The electrochemistry of noble metal electrodes in aprotic organic solvents containing lithium salts. J Electroanal Chem Interf Electrochem 297:225-244

Publisher's Note Springer Nature remains neutral with regard to jurisdictional claims in published maps and institutional affiliations. 